\title{
Liquid-crystal equilibrium application for 2,3-DNT initial thermal decomposition analysis
}

\author{
T. Gołofit ${ }^{1}$ - T. Zielenkiewicz ${ }^{2}$
}

Received: 17 September 2015/Accepted: 15 January 2016/Published online: 3 February 2016

(c) The Author(s) 2016. This article is published with open access at Springerlink.com

\begin{abstract}
Dinitrotoluene (2,3-DNT) thermal decomposition and its products were studied. Main attention was paid on the initial stage of decomposition, because the degradation of even a few percent of high energetic compound may cause significant hazard. Partial decomposition of 2,3-DNT was performed conditioning at the temperature range of $457-568 \mathrm{~K}$. Impurities production at the initial stage of decomposition was determined by the analysis of melting enthalpy decrease with cryometric method. Mean self-aggregation number of the initial substance was defined and determined to estimate the molecular mass of products of 2,3-DNT thermal conditioning. MALDI TOF method was used for independent molecular mass verification. 2,3-DNT is thermally stable substance. Heating of its sample from the ambient temperature to $486 \mathrm{~K}$ with the heating rate of $2 \mathrm{~K} \mathrm{~min}^{-1}$ does not cause thermal decomposition. Very good reproducibility of melting process performed on the same sample was obtained. Only prolonged conditioning at raised temperature leads to initial substance loss. Two competitive reactions, aggregation and decomposition, were run during 2,3-DNT thermal conditioning. Heating with low heating rate leads to products with higher molecular masses. Two different results prove that: MALDI TOF analysis and the melting enthalpy decrease which is higher than the increase in impurities content determined with cryometric method. Mass spectrum of the thermally conditioned 2,3DNT samples includes strong signals with (among others)
\end{abstract}

T. Gołofit

tomgol@ch.pw.edu.pl

1 Faculty of Chemistry, Warsaw University of Technology, Noakowskiego 3, 00-664 Warsaw, Poland

2 Faculty of Wood Technology, Warsaw University of Life Sciences, Nowoursynowska 166, 02-787 Warsaw, Poland following $m / z$ values: 551, 687, 1062, 1137, 1211. Formed macromolecular compounds were stable until the temperature of $500 \mathrm{~K}$.

Keywords Dinitrotoluene - Thermal decomposition . DSC $\cdot$ MALDI TOF $\cdot$ Nitro-compounds aggregation

\section{Introduction}

Thermal explosion is the strongest hazard during nitrocompounds storage and exploitation. It follows as a result of the cumulation of the heat released in the decomposition reaction [1]. Uncontrolled nitro-compounds decomposition may lead to the accident [2]. Toluene derivatives with two nitro-groups (DNT) are examples of nitro-compounds. They are used mainly as the half products in chemical synthesis, for instance, polymers [2,3]. Studies on the modification and optimization of DNT synthesis are still performed regarding high scale of its production [4]. The knowledge about parameters determining thermal stability of dinitrotoluenes allows safe performance of technological processes with their participation. Number of theoretical studies describing possible stages of toluene nitro-derivatives decomposition $[5,6]$ is available in the literature. Differential scanning calorimetry (DSC) is most often used technique for the analysis of toluene nitro-derivatives thermal decomposition [7-9]. Adiabatic reactionary calorimeter (ARC) is also used for this purpose [7], and decomposition products may be analyzed with mass spectrometer [10]. The first stage of the aromatic nitro-compounds decomposition differs dependently on the type and position of substituent. Nitro-group without substituents in ortho position may undergo homolytic separation from the ring and following regroup to nitrite group $[5,6,11]$. 
Two nitrate groups in ortho position may react with each other forming benzofurazan and benzofuroxan [10, 12]. Nitro-group next to the methyl group forms anthranil $[13,14]$. Reactions between two DNT molecules may lead to the azoxy-bond formation [15]. In Duh et al. [7], onset decomposition temperatures of only three DNT isomers may be found: 2,4-dinitrotoluene (2,4-DNT), 2,6-dinitrotoluene (2,6-DNT) and 3,4-dinitrotoluene (3,4-DNT). The lowest decomposition temperature was denoted for 2,4DNT $(523 \mathrm{~K})$ and the highest for 2,6-DNT (563 K). This temperature equals $553 \mathrm{~K}$ for 3,4-DNT. Two of DNT isomers were studied by Ando [8], and 2,4-DNT onset decomposition temperature was lower in relation to 3,4 DNT. It is assumed that homolytic collapse of C-H bond in methyl group is the first decomposition stage in case of ortho-nitrotoluenes and the next one-hydrogen addition to the oxygen atom from nitro-group [9, 16]. Then, the number of consequent reactions follows with gaseous products as a result. Case's studies [17] indicate that stable DNT decomposition product in solid phase exists below $573 \mathrm{~K}$, which decomposes immediately to gaseous products above this temperature. Maksimov [18] calculated kinetic parameters of the thermal decomposition of 2,4DNT, 2,6-DNT and 3,5-DNT using manometric (SMM) method. Decomposition rate constant at $500 \mathrm{~K}$ is the highest for 2,4-DNT and the lowest for 3,5-DNT.

The analysis of total sample decomposition is the most often described method of the analysis of different compounds thermal stability [19-21]. This method allows calculation of kinetic parameters on the basis of calorimetric measurement performed on the sample with mass of cca. $1 \mathrm{mg}$. Unfortunately, this method generates problems with the proper decomposition enthalpy determination. Samples with minute masses (cca. $0.5 \mathrm{mg}$ for hermetic pans, 1-2 mg for pans with the hole) should be used to avoid the destruction of measurement device. Additionally, such a sample is unrepresentative because of heterogeneity on this mass level. Thermal effect of total decomposition covers mainly temporary decomposition products (94\% of TNT disappears until $64 \%$ of the decomposition thermal effect is released [22]). From the other hand, application of pans with the hole leads in many cases to the overlapping of evaporation and decomposition process of the sample (for instance, DNT).

Already, small conversion degree may cause the thermal explosion [23]. That is why detailed studies of initial stage of the thermal decomposition are significant. Special attention must be paid on the low temperature decomposition, in conditions as much as possible similar to technological operations and storage. Cryometry is one of often used methods of the analysis of impurities production at the initial stage of decomposition [24, 25]. Liquid-crystal equilibrium is very sensitive for impurities concentration and enables studying decomposition process at the initial stage.

The aim of this paper is to analyze the initial stage of the thermal decomposition of 2,3-DNT with the application of liquid-crystal equilibrium and partial decomposition method. The determination of the influence of process conditions on products forming is the additional purpose.

\section{Experimental}

\section{Materials}

2,3-Dinitrotoluene was synthesized in the Technical Military Academy in Warsaw in 1960s. Physico-chemical parameters were determined and compared with literature values: melting temperature $T_{\mathrm{m}}=332.7,329.7 \mathrm{~K}$ [26], melting enthalpy $\Delta H_{\mathrm{m}}=16.1,17.5 \mathrm{~kJ} \mathrm{~mol}^{-1}$ [26]. Purity of analyzed compound was determined with cryometric method (99.9 mol\%) and with the application of gaseous chromatography (99.9\%).

\section{Method used}

Measurements were taken on a heat-flux DSC 605 UNIPAN calorimeter. The calibration was performed with gallium, indium, cadmium, tin, zinc naphthalene and benzoic acid. Purity values of used metals were above $99.999 \%$. Purity values of organic substances used were higher than $99.95 \%$. Measurements were taken using hermetic aluminum pans with heating rate of $2 \mathrm{~K} \mathrm{~min}^{-1}$. Samples were sealed under reduced pressure of about $1.3 \mathrm{kPa}$. Calculations of kinetic parameters were made independently with two methods: partial decomposition and cryometric method.

Partial decomposition method allows the calculation of kinetic parameters on the basis of calorimetric measurements taken on the sample with mass of over a dozen of mg. Disadvantages of total decomposition methods are eliminated then. The measurement should be terminated at the initial stage of decomposition to avoid device destruction. Kinetic parameters were determined with Borchardt-Daniels method. Determined kinetic parameters do not relate to elementary reaction description because of high complexity of the decomposition process, many competitive and consequent reactions during nitro-compounds decomposition. This is only the mathematic description of experimental data. To emphasize this, the exponential factor is called as apparent activation energy $a E_{\mathrm{a}}$ in further part of this paper. This value may be used for the analysis of the hazard related to nitro-compounds thermal decomposition. 
The application of cryometric method to kinetic parameters calculation consisted on studies of the impurities concentration increase in consecutive melting processes of the same sample which were conducted up to arbitrarily chosen temperature. Cyclic measurements of the melting process followed by fast heating to high temperatures (above $450 \mathrm{~K}$ ) and isothermal conditioning of the sample were performed. Aluminum pan was opened after a cycle of a few to dozens of melting-conditioning measurements, to analyze decomposition products. As the literature data [27, 28] indicate the possibility of molecules aggregation during conditioning at high temperatures, reclaimed samples were analyzed with the MALDI TOF technique to determine molecular masses of compounds formed as a result of the decomposition. Additionally, thermal conditioning of studied compound in high-pressure tight closed pan was performed at similar temperatures. These samples were also analyzed with MALDI TOF. The analysis of molecular masses of products was performed in the Centre of Molecular and Macromolecular Studies in Lodz. Kratos Kompact MALDI four device was used with nitrogen laser (wavelength $227 \mathrm{~nm}$ ), $3 \mathrm{~ns}$ impulse, positive polarization, $20 \mathrm{kV}$ of acceleration voltage, 200 impulses per spectrum. Decomposition products were dissolved in the acetone before the analysis.

\section{Method background}

The method for the analysis of the thermal decomposition process at the initial stage (sample mass of about dozen of mg) was developed in High Energetic Materials Division (Faculty of Chemistry, Warsaw University of Technology) [29-31]. The measurement of sample decomposition was terminated when the calorimetric signal increase exceeded critical thermal power, experimentally determined. Above this critical value, calorimeter could be destroyed as the result of reaction going out of the control. Sample reaction degree during measurement is very low for applied technique; that is why zero-order transition model was assumed to determine kinetic parameters $A_{\mathrm{p}} \mathrm{i} a E_{\mathrm{a}}$. Decomposition enthalpy $\Delta H_{\mathrm{p}}$ is related to $\alpha_{\mathrm{p}}$. Conversion degree $\alpha_{\mathrm{p}}$ equals 1 at the moment of the measurement termination, even though real conversion degree is very small. That is why $\alpha_{\mathrm{p}}$ is called the apparent conversion degree. The dependence of real and apparent conversion degree is as follows:

$\alpha=\alpha_{\mathrm{p}}\left[\frac{\Delta H_{\mathrm{p}}}{\Delta H_{\mathrm{t}}^{0}}\right]$

where $\Delta H_{\mathrm{t}}^{0}$-decomposition enthalpy of whole sample $(\alpha=1)$.

The conversion degree $\left(\alpha_{\mathrm{p}}\right)$ is proportional to the real conversion degree $(\alpha)$ because the enthalpy ratio in brackets is constant. It arises that reaction rates determined on the basis of these degrees are also proportional. The dependence between reaction rates is presented with Eq. (2):

$\frac{\mathrm{d} \alpha}{\mathrm{d} t}=\frac{\mathrm{d} \alpha_{\mathrm{p}}}{\mathrm{d} t}\left(\frac{\Delta H_{\mathrm{p}}}{\Delta H_{\mathrm{t}}} A \mathrm{e}^{\mathrm{E}_{\mathrm{a}} / \mathrm{RT}}=\left(\frac{\Delta H_{\mathrm{p}}}{\Delta H_{\mathrm{t}}}\right) A_{\mathrm{p}} \mathrm{e}^{\mathrm{E}_{\mathrm{a}} / \mathrm{RT}}\right)$

where $A$-preexponential factor for real conversion degree and $A_{\mathrm{p}}$-preexponential factor for apparent conversion degree.

The total decomposition enthalpy $\left(\Delta H_{\mathrm{t}}^{0}\right)$ can be obtained using DSC measurements of small samples complete decomposition (below $0.5 \mathrm{mg}$ ). But the loss of initial substance after the measurement may be observed on the change of the melting enthalpy. To calculate the conversion degree after DSC measurement $\left(\alpha_{\mathrm{f}}\right)$ changes of the melting enthalpy should be exploited. For this purpose, the assumption should be made that impurities do not created solid solution and are totally soluble in the liquid phase. The final conversion degree of the partial decomposition $\left(\alpha_{\mathrm{f}}\right)$ can be calculated using the following equation:

$\alpha_{\mathrm{f}}=\frac{\Delta H_{\mathrm{m}}-\Delta H_{\mathrm{n}}}{\Delta H_{\mathrm{m}}}$

where $\Delta H_{\mathrm{m}}$ is the melting enthalpy before thermal decomposition, measured in the first DSC run, and $\Delta H_{\mathrm{n}}$ is the melting enthalpy in a subsequent measurement made on the same sample. In this case, conversion degree equals the nominal molar ratio of impurities.

$\alpha_{\mathrm{f}}=x=\sum_{i} i x_{\mathrm{i}}$

where $x_{i}$-molar ratio of the decomposition product " $i$ ". For the determined value of $\alpha_{\mathrm{f}}$, the condition $\alpha_{\mathrm{p}}=1$ must be fulfilled. That is why following dependence arises:

$\alpha_{\mathrm{f}}=\frac{\Delta H_{\mathrm{p}}}{\Delta H_{\mathrm{t}}}$

and also:

$A=\alpha_{\mathrm{f}} A_{\mathrm{p}}$

where $A$-preexponential factor for the real conversion degree and $A_{\mathrm{p}}$-preexponential factor for the apparent conversion degree.

Liquid-crystal equilibrium is very sensitive for the liquidphase impurities. Small amount of impurities significantly decreases melting temperature of the substance. Molar concentration of impurities - the purity of studied compoundmay be determined with following cryometric equation:

$T_{\mathrm{m}}=T_{\mathrm{m}}^{0}-\frac{R \times\left(T_{\mathrm{m}}^{0}\right)^{2}}{\Delta H_{\mathrm{m}}} \times x \times \frac{1}{F}$

where $F$-sample melting degree, $x$-real molar ratio of impurities, $T_{\mathrm{m}}^{0}$-melting temperature of ideally pure 
substance, $T_{\mathrm{m}}$ - sample melting temperature and $\Delta H_{\mathrm{m}}-$ melting enthalpy. Following assumption must be introduced: Components totally mix in the liquid phase and totally do not mix in the solid phase; melting enthalpy of components in analyzed temperature range is approximately independent on the temperature; the solution may be described with the perfect solution model. Where the molar ratio of impurities is known, the purity of the sample may be determined with the following equation:

$P=(1-x) \times 100 \%$

The sample is polluted by the decomposition products during thermal analysis. When the measurement to the arbitrarily chosen final temperature $T_{\mathrm{f}}$ is performed, impurities increase $(\Delta x)$ follows. It equals the difference between the molar impurities ratio of the sample taken for studies $x^{0}$ and the sample after the decomposition $x_{\mathrm{f}}$. The impurities increase is equal to the real molar impurities ratio $x$ connected with the thermal decomposition.

$\Delta x=x^{0}-x_{\mathrm{f}}=\sum_{i} x_{\mathrm{i}}$

where $x_{\mathrm{i}}$-molar ratio of the decomposition product " $i$ ". Making the assumption that one molecule of analyzed substance forms on molecule of the impurity during decomposition, and the rest of volatile impurities are only in gaseous phase, the value of real molar ratio of impurities $(\Delta x)$ should equal to conversion degree $\alpha_{\mathrm{f}}$. If the value of $(\Delta x)$ is higher than $\alpha_{\mathrm{f}}$ parameter, then it means that from one molecule of analyzed compound more than a one molecule of impurities is formed in liquid phase. On the other hand, when value of $(\Delta x)$ is lower than $\alpha_{\mathrm{f}}$ value, then it means that molecules of decomposition products in the liquid phase join and create compounds with molecular mass higher than initial compound. Size of these molecules could be defined with so-called mean self-aggregation number $\lambda$ [32-34], which may be calculated on the basis of following equation:

$\Delta x=\frac{\alpha_{\mathrm{f}}}{\lambda-\lambda \times \alpha_{\mathrm{f}}+\alpha_{\mathrm{f}}}$

\section{Results and discussion}

\section{Initial decomposition}

In order to verify the usability of liquid-crystal equilibrium for impurities production determination at the initial stage of the decomposition, series of three measurements of the melting process of the same 2,3-DNT sample was made. The first and the third measurement was terminated at
$366 \mathrm{~K}$, the second-at $486 \mathrm{~K}$. Results of these analyses are presented in Fig. 1.

No deviation from DSC curve at high temperatures, which would indicate the exothermal decomposition, was denoted in case of the run terminated at $486 \mathrm{~K}$. Very good repeatability of the melting process was obtained for measurements taken on the same sample. Solid-solidphase transition was observed for this compound with the melting temperature $T=307.2 \mathrm{~K}$ and melting enthalpy $\Delta H=4.58 \mathrm{~kJ} \mathrm{~mol}^{-1}$.

Another series of the melting process after isothermal conditioning at 457,467 and $477 \mathrm{~K}$ was performed. Results are presented in Fig. 2.

Prolonged conditioning at the temperature of $457 \mathrm{~K}$ (350 $\mathrm{min})$ and $467 \mathrm{~K}(810 \mathrm{~min})$ did not cause visible increase in impurities determined with cryometric method. However, insignificant but systematic decrease in melting enthalpy from 17.6 to $16.6 \mathrm{~kJ} \mathrm{~mol}^{-1}$ in the 10 th run was observed. Significant change in the melting process took place only in the 11th. It was related to measurement pan decompression and sample mass loss during conditioning. The last conditioning process performed on the sample closed in non-hermetical pan caused a significant increase in impurities determined with cryometric method, but did not cause the decrease in the melting enthalpy. Slow decomposition of the sample conditioned at raised temperature was the reason of the enthalpy decrease in runs $1-10$. The lack of purity changes determined with cryometric method indicates that decomposition products at the initial stage of decomposition form separate phase. The first conditioning process at $477 \mathrm{~K}$ caused measurement pan decompression, related to high vapor pressure and gaseous products of decomposition. Following conditioning process caused the decrease in the sample purity from

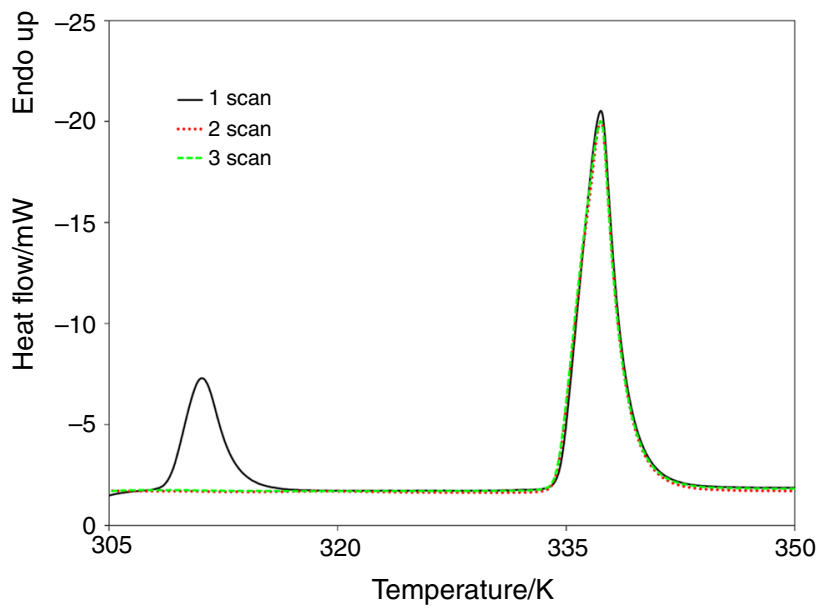

Fig. 1 DSC curves of the melting process and solid-solid-phase transition of $15 \mathrm{mg}$ 2,3-DNT sample 


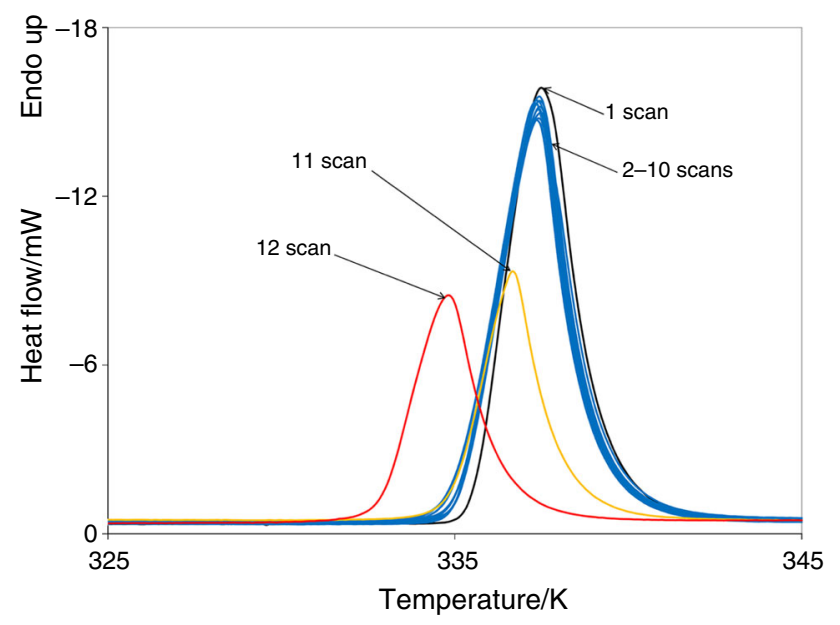

Fig. 2 DSC curves of $10 \mathrm{mg}$ 2,3-DNT sample melting process without conditioning (scan 1), after 30-, 60-, 100- and 160-min conditioning at $457 \mathrm{~K}$ and following $30,60,120,240$ and $360 \mathrm{~min}$ at $467 \mathrm{~K}$ (scan 2-10) and following 40 and $160 \mathrm{~min}$ at $477 \mathrm{~K}$ (scan 11-12)

99.91 to $98.31 \%$ connected with low molecular mass impurities soluble in 2.3-DNT.

Measurements of the melting process of 2,3-DNT samples after $180 \mathrm{~min}$ of isothermal conditioning in highpressure pans at 473, 483 and $493 \mathrm{~K}$ were performed. The results of the melting process DSC analysis of conditioned samples are presented in Fig. 3.

Significant decrease in melting enthalpy related to the sample decomposition was the result of conditioning in high-pressure pans. The lack of any melting temperature shift indicates that formed decomposition products are in the separate phase. Obtained results (Figs. 2, 3) prove that separate phase of decomposition products is created during the process performed in hermetical conditions. Decompression of measurement pan causes the loss of gaseous

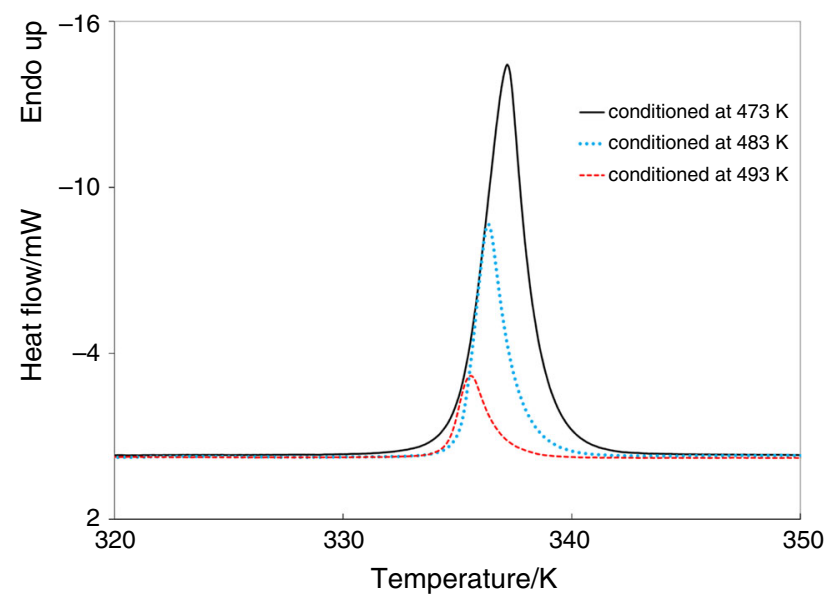

Fig. 3 DSC curves of 2.3-DNT melting process after 180-min conditioning at $473,483,493 \mathrm{~K}$ decomposition products and decomposition of formed earlier aggregated decomposition products and creation of low molecular mass compounds, which pollute liquid phase of 2,3-DNT. The decrease in bulk density of samples with the increase in conditioning temperature was observed. Cca. $20 \mathrm{mg}$ of the sample before conditioning may be placed in DSC pan and only $1 \mathrm{mg}$ of the sample after conditioning at the highest temperature (493 K).

\section{Partial decomposition}

The analysis of strong exothermal decomposition of 2,3DNT is hard to perform because of high vapor pressure and gaseous products of the decomposition. High pressure inside hermetic measurement pan made of aluminum foil caused the deformation and decompression at higher temperatures. Thermo-analytic curve which is easy to interpret may be obtained only when the measurement is terminated at the initial stage of decomposition. Figure 4 shows exemplary curves of melting and partial decomposition of 16 mg 2,3-DNT sample.

Specific deviation from the linear character may be observed on the base line of the thermo-analytic curve after melting peak. It is related to exothermal decomposition of the compound. The temperature of non-extrapolated decomposition onset $T_{\mathrm{p}}=471 \mathrm{~K}$ was determined, and the apparent activation energy was calculated-aE $=187$ $\mathrm{kJ} \mathrm{mol}^{-1}$. The melting process in the 2 nd run started at lower temperature and lower thermal effect was denoted, which is caused by initial substance decomposition and impurities production in the 1st run. Thermal decomposition of 2,3-DNT appears at temperature much higher than melting point. Impurities production was determined with cryometric method [25] $\Delta x=0.0238$; additionally, mean

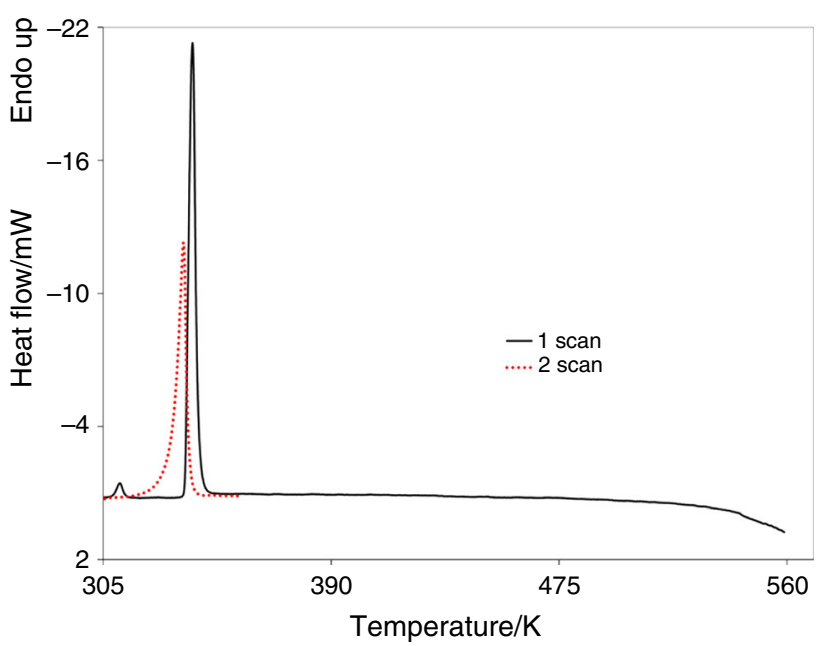

Fig. 4 DSC curves of melting and partial decomposition of $16 \mathrm{mg}$ 2,3-DNT sample 
aggregation number was calculated- $\lambda=5.73$. It is mean number of initial substance molecules which underwent the aggregation into one molecule of decomposition product during partial decomposition. This value corresponds to mean molecular mass of cca. $1000 \mathrm{u}$.

\section{Thermal decomposition products}

All measurements of the partial decomposition showed that melting enthalpy decrease after conditioning is much higher than increase in impurities. It may be connected with creation of impurities with molecular mass higher than initial substance. To verify this hypothesis, the cycle of measurements of the melting process and thermal conditioning at the temperature below $500 \mathrm{~K}$ was performed. Following observations were made on the basis of these measurements. Firstly, isothermal conditioning of the sample does not cause any thermal effect, even if following melting process measurement showed advanced decomposition. It indicates that reactions at the initial stage of decomposition proceed with low thermal effect. Secondly, fast heating often caused the decompression of the pan already below $500 \mathrm{~K}$, while slow heating $\left(2 \mathrm{~K} \mathrm{~min}^{-1}\right)$ could be successfully performed until the temperature above $550 \mathrm{~K}$. Heating with low rate of the temperature increase causes reactions leading to products of higher molecular mass. Additionally, a few of initial isothermal runs caused the increase in determined with cryometric method purity. It decreased only after following measurements. It indicates for the exclusion of impurities from the liquid phase or the reaction leading to macromolecular products.

MALDI TOF technique was applied to verify the possibility of macromolecular substances creation. Figure 5 presents mass spectrum of the sample without conditioning, sample 1 after non-isothermal conditioning with heating rate of $2 \mathrm{~K} \mathrm{~min}^{-1}$ from the ambient temperature to the temperature of the visible exothermal decomposition $\left(T_{\mathrm{f}}=568 \mathrm{~K}\right)$ and the sample 2 conditioned within $180 \mathrm{~min}$ at $493 \mathrm{~K}$ in high-pressure pan.

Mass spectrum of the standard sample contains insignificant signals with high masses $\mathrm{m} / \mathrm{z}$ (above 500). Analyzed DNT was stored a few dozens of years at the ambient temperature. Reaction of molecules linking was possible in these conditions. Mass spectra of samples thermally conditioned contain strong signals at $\mathrm{m} / \mathrm{z}$ values of (among others) 551, 687, 1062, 1137, 1211. The results show that molecular mass of initial decomposition products is a few times higher than molecular mass of DNT. Macromolecular substances with the same molecular mass are observed on all presented spectra. Obviously, the intensities of peaks for standard sample are much lower in relation to conditioned samples. It testifies that the

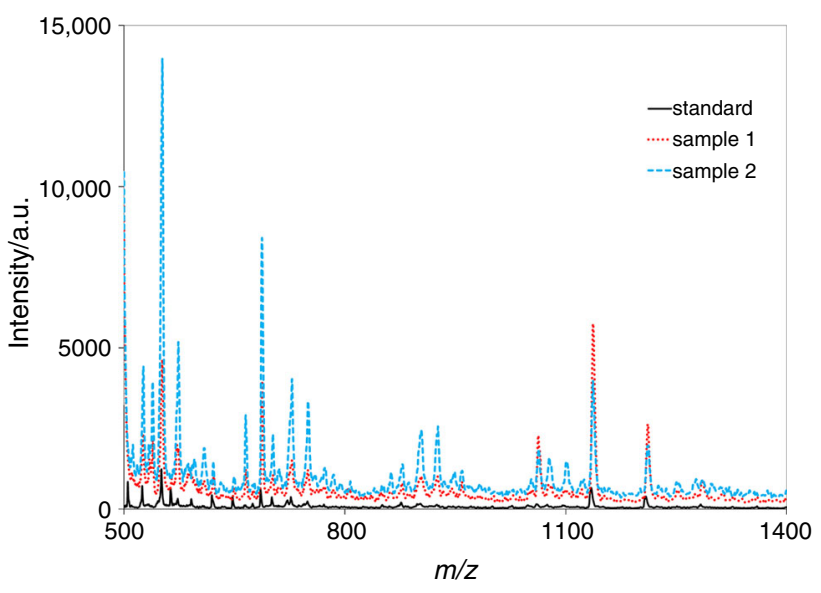

Fig. 5 Mass spectra of 2,3-DNT samples without conditioning (standard), after non-isothermal conditioning up to $T_{\mathrm{f}}=568 \mathrm{~K}$ (sample 1), after $180 \mathrm{~min}$ of conditioning at $493 \mathrm{~K}$ in high-pressure pan

mechanism of the decomposition at the ambient and increased temperature is similar. The intensities of signals with high values of $\mathrm{m} / \mathrm{z}$ in case of the sample heated $2 \mathrm{~K} \mathrm{~min}^{-1}$ up to $568 \mathrm{~K}$ are higher in relation to the same signals for fast heated sample and conditioned at $493 \mathrm{~K}$. It means that heating rate significantly influences for the molecular mass of decomposition products. Obtained results indicate for two competitive reactions leading to macromolecular and low molecular mass products. Slow heating promotes the creation of thermally stable macromolecular substances. Fast heating causes formation of compounds with low molecular mass.

Conditioning ( $3 \mathrm{~h}$ ) of 2,3-DNT samples in high-pressure pans at the temperature of 473,483 and $493 \mathrm{~K}$ was performed. Obtained mass spectra of conditioned samples are presented in Fig. 6.

Macromolecules with the same molecular mass were observed in all samples, but signal intensities changed.

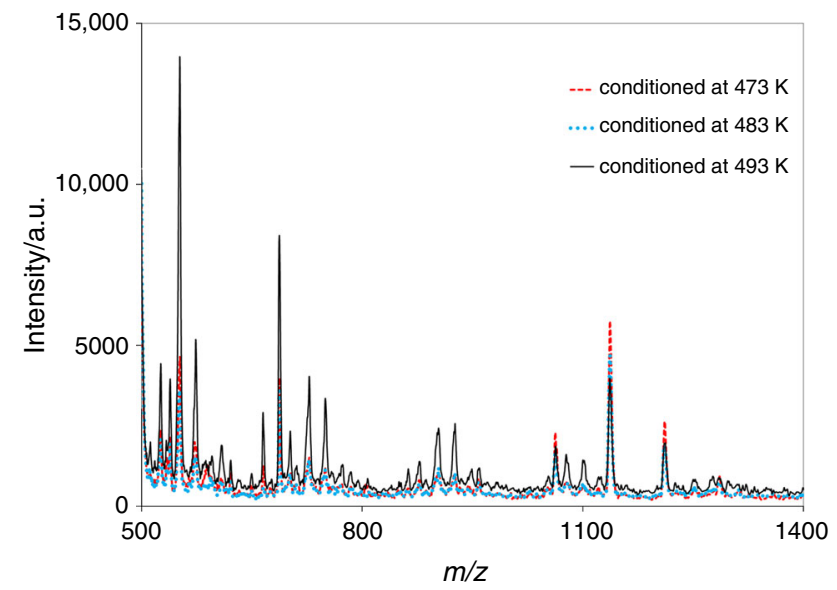

Fig. 6 Mass spectra of 2,3-DNT samples after 180-min conditioning at 473,483 and $493 \mathrm{~K}$ in high-pressure pan 
Fig. 7 Proposed products of 2,3-DNT aggregation

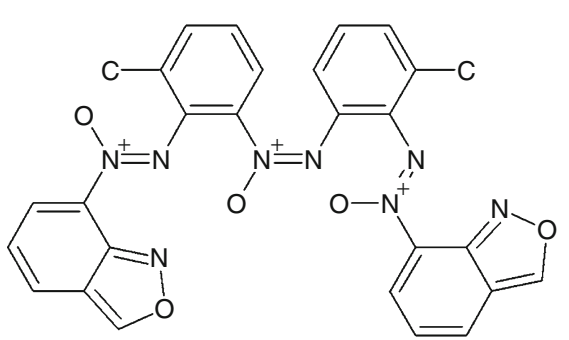

$\mathrm{Mn}=551.5$

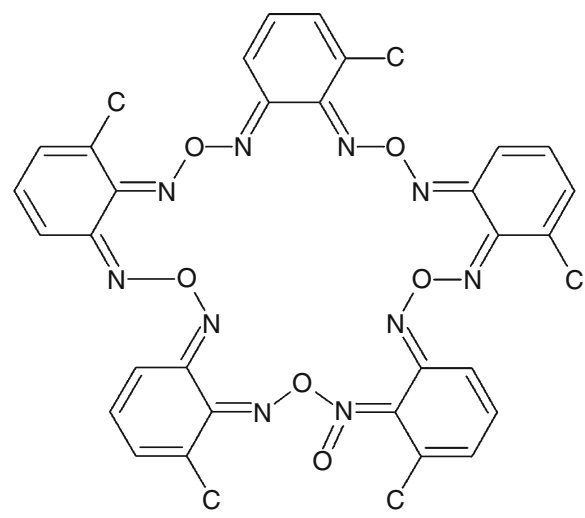

$\mathrm{Mn}=686.7$

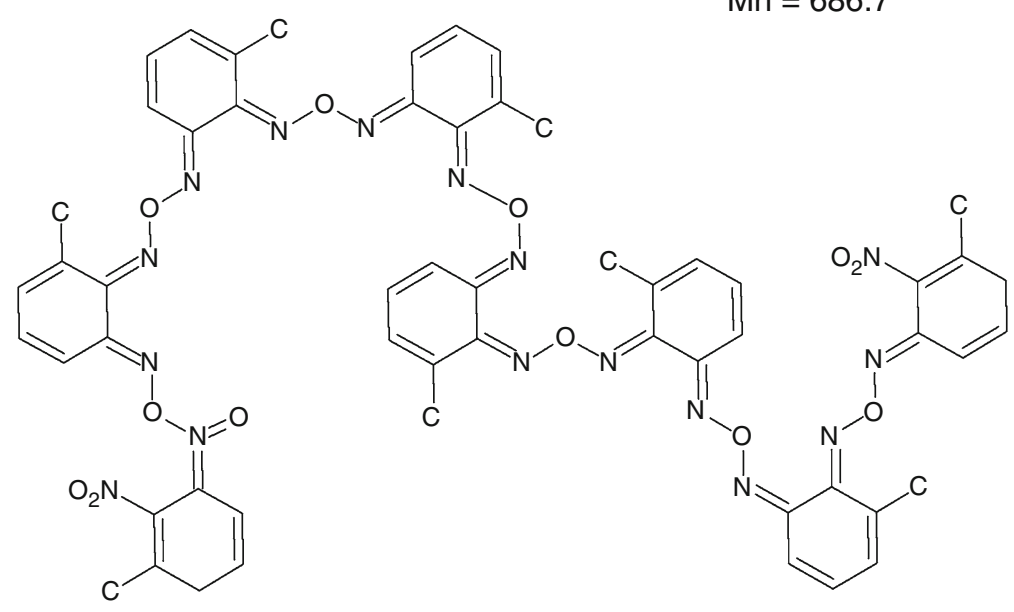

$\mathrm{Mn}=1139.1$

Higher $\mathrm{m} / \mathrm{z}$ signals below 1000 and lower $\mathrm{m} / \mathrm{z}$ signals above 1000 were observed in case of conditioning at $493 \mathrm{~K}$ in relation to conditioning at $473 \mathrm{~K}$. It indicates that lower temperature of conditioning promotes the formation of products with higher molecular masses.

Assuming the opportunity of the reaction between substituents of different 2,3-DNT molecules, the possibility of creation of molecules with determined molecular masses was analyzed. Examples of molecules are presented in Fig. 7.

Molecular masses of proposed products of 2,3-DNT aggregation are well compatible with analyzed samples mass spectra. The analysis of presented molecules structure indicates that reactions between nitro-groups from different molecules are preferred.

\section{Conclusions}

2,3-Dinitrotoluene is the thermally stable substance. Only prolonged conditioning in the increased temperature leads to original substance loss. DSC analysis showed three transitions of this compound in the increased temperature: solid-solid transition, $T=307.2 \mathrm{~K}, \Delta H=4.58 \mathrm{~kJ} \mathrm{~mol}^{-1}$, melting process $T_{\mathrm{m}}=332.7 \mathrm{~K}, \Delta H_{\mathrm{m}}=16.1 \mathrm{~kJ} \mathrm{~mol}^{-1}$, and decomposition with non-extrapolated decomposition beginning in $T_{\mathrm{p}}=471 \mathrm{~K}$, and apparent activation energy $a E_{\mathrm{a}}=187 \mathrm{~kJ} \mathrm{~mol}^{-1}$.

Molecules of 2,3-DNT are polar, and their dipole moment may be responsible for their trend to aggregate. High polarity leads to molecules approach and intermolecular reaction acts. The action of the temperature in the range of melting point and $480 \mathrm{~K}$ does not cause advanced decomposition, but-on the contrary-aggregation is the dominant reaction. It was proved by MALDI TOF analysis and the enthalpy decrease higher than determined with cryometric method increase in impurities content. The decrease in determined molar impurities content may be connected with their low solubility in the liquid phase of DNT. It additionally confirms the aggregation-macromolecular compounds are not well soluble in liquid organic substances.

The analysis of decomposition products at ambient and increased temperature indicates that the mechanism of 2,3DNT does not depend on the temperature and leads to macromolecular substances. Formation of compounds with 
higher molecular mass $(m / z>1000)$ is promoted in lower temperatures.

Performed analysis suggests that rapid heating of the material is especially dangerous during storage and technological operations with 2,3-DNT participation. Heat explosion is very probable in these conditions.

Open Access This article is distributed under the terms of the Creative Commons Attribution 4.0 International License (http://crea tivecommons.org/licenses/by/4.0/), which permits unrestricted use, distribution, and reproduction in any medium, provided you give appropriate credit to the original author(s) and the source, provide a link to the Creative Commons license, and indicate if changes were made.

\section{References}

1. Semenov NN. Chemical kinetics and chain reactions. London: Oxford University Press; 1935.

2. Zhang GZ. Bin Cause of "5.11" explosion in Cangzhou Dahua TDI branch factory. Xiaofang Kexue Yu Jishu. 2008;27(8): 615-7.

3. Bock M, Baumann R, Franzke A, Stroefer E, Theis G. Method for the combined production of diisocyanates and/or polyisocyanates and glycols. WO Patent 2011051314 A1; DE; 2011.

4. Adamiak J, Skupinski W. Dinitrotoluene synthesis using solid state catalysts $-\mathrm{MoO}_{3} / \mathrm{SiO}_{2}$ and $\mathrm{H}_{3} \mathrm{PO}_{4} / \mathrm{MoO}_{3} / \mathrm{SiO}_{2}$. Cent Eur $\mathrm{J}$ Energ Mater. 2010;7(4):301-11.

5. Tanaka G, Weatherford C. Decomposition mechanisms of dinitrotoluene. Int J Quantum Chem. 2008;108:2924-34

6. Fayet G, Joubert L, Rotureau P, Adamo C. A theoretical study of the decomposition mechanisms in substituted o-nitrotoluenes. J Phys Chem A. 2009;113(48):13621-7.

7. Duh Y, Lee C, Hsu C, Hwang D, Kao C. Chemical incompatibility of nitrocompounds. J Hazard Mater. 1997;53:183-94.

8. Ando T, Fujimoto Y, Morisaki S. Analysis of differential scanning calorimetric data for reactive chemicals. J Hazard Mater. 1991;28(3):251-80.

9. Minier LM, Brower KR, Oxley JC. The role of intermolecular reactions in thermolysis of aromatic nitro compounds in supercritical aromatic solvents. J Org Chem. 1991;56:3306-14.

10. Fields EK, Meyerson S. Arylation by aromatic nitro compounds at high temperatures. II. Nitrobenzene alone and with benzene and benzene-d6. J Am Chem Soc. 1967;89:3224-8.

11. Maksimov YY, Sorochkin SB, Titov SV. Kinetics and mechanism of the thermal decomposition of mononitrobenzene in vapors. Tr Mosk Khim Technol Inst im D I Mendeleeva. 1980;112:26-31.

12. Bliss DE, Christian SL, Wilson WS. Impact sensitivity of polynitroaromatics. J Energ Mater. 1991;9:319-45.

13. Tsang W, Robaugh D, Mallard WG. Single-pulse shock-tube studies on $\mathrm{C}-\mathrm{NO}_{2}$ bond cleavage during the decomposition of some nitro aromatic compounds. J Phys Chem. 1986;90(22): 5968-73.

14. He YZ, Cui JP, Mallard WG, Tsang W. Homogeneous gas-phase formation and destruction of anthranil from o-nitrotoluene decomposition. J Am Chem Soc. 1988;110(12):3754-9.

15. Shin KH, Lim Y, Ahn JH, Khil J, Chad CJ, Hur HG. Anaerobic biotransformation of dinitrotoluene isomers by Lactococcus lactis subsp. lactis strain 27 isolated from earthworm intestine. Chemosphere. 2005;61(1):30-9.
16. Shackelford SA. Mechanistic investigations of condensed phase energetic material decomposition processes using the kinetic deuterium isotope effect. In: Bulusu SN, editor. Chemistry and physics of energetic materials: proceedings of the NATO Advanced Study Institute. Dordrecht: Kluwer Academic Publishers; 1990. p. 413-32.

17. Case JL, Carr RVC, Simpson MS. Modeling to gain insight into thermal decomposition of dinitrotoluene. ACS Symp Ser. 1996;623:174-86.

18. Maksimov YY. Effect of the vapor-liquid state of aggregation on the thermal decomposition rate of aromatic polynitro compounds. Zh Fiz Khim. 1971;45(4):793-6.

19. Gołofit T, Zyśk K. Thermal decomposition properties and compatibility of CL-20 with binders HTPB, PBAN, GAP and polyNIMMO. J Therm Anal Calorim. 2015;119(3):1931-9.

20. Howell BA, Sun W. Thermal degradation of esters/ethers derived from tartaric acid. J Therm Anal Calorim. 2015;122:1167-75.

21. Wiecińska $P$. Thermal degradation of organic additives used in colloidal shaping of ceramics investigated by the coupled DTA/ TG/MS analysis. J Therm Anal Calorim. 2015;. doi:10.1007/ s10973-015-5075-1.

22. Janney IL, Rogers RN. Experimental thermochemical observations of condensed-phase reactions. In: Proceedings of the 11th North American thermal analysis society conference, vol. II; 1982. p. 643-649.

23. Abramov VG, Vaganova NI. Effect of a side reaction with small heat liberation on the critical thermal-explosion condition of the main self-catalyzed reaction. Fiz Goreniya Vzryva. 1978;14(5): $135-41$.

24. Ksiazczak A, Ksiazczak T, Zielenkiewicz T. Influence of purity on the thermal stability of solid organic compounds. J Therm Anal Calorim. 2004;77:233-42.

25. Ksiazczak A, Ksiazczak T. Kinetic data of low-temperature thermal decomposition of $N, 2,4,6$-tetranitro- $N$-methylaniline. Thermochim Acta. 1996;284(2):299-308.

26. Borchardt HJ, Daniels F. Application of differential thermal analysis to the study of reaction kinetics. J Am Chem Soc. 1957;79:41-6.

27. Dacons JC, Adolph HG, Kamlet MJ. Novel observations concerning the thermal decomposition of 2,4,6-trinitrotoluene. J Phys Chem. 1970;74(16):3035-40.

28. Adams GK, Rowland PR, Wiseman LA. Ministry of supply report A. C. 3982, Great Britain, 1943.

29. Ksiazczak A, Ksiazczak T. Influence of DSC measurement conditions on kinetic parameters of thermal decomposition of 2,4,6trinitrotoluene. J Therm Anal Calorim. 2000;60(1):25-33.

30. Drożdzewska K, Ksiazczak A, Ksiazczak T. Thermal decomposition of triazine herbicides I. 1,2-(4-chloro-6-ethylamino-1,3,5triazin-2-ylamino)-2-methylpropionitrile (cyanazine). J Therm Anal Calorim. 2000;60(1):103-10.

31. Ksiazczak A, Maranda A, Rosenkiewicz D. Thermal analysis of binary systems explosive-lead compound. J Thermal Anal. 2000;60:97-102.

32. Kempter H, Mecke R, Teil B. Spectroscopic determination of association equilibrium. Z Phys Chem. 1940;46:229-41.

33. Książczak A, Anderko A. Prediction of solid-liquid equilibria on the basis of pure compound properties. Fluid Phase Equilib. 1987;35:127-51.

34. Książczak A. Effect of auto-association on solid-liquid equilibrium. Fluid Phase Equilib. 1986;28:39-56. 